\title{
Magnitude and reasons of initial default among new sputum positive cases of pulmonary tuberculosis under RNTCP in a district of West Bengal, India
}

\author{
Amitabha Mandal $^{1}$, Mausumi Basu², Palash Das ${ }^{3}$, Sujishnu Mukherjee ${ }^{4}$, Sibasis Das ${ }^{5}$, Nirmalya Roy $^{6}$ \\ ${ }^{1}$ Deputy CMOH-2, Malda, West Bengal; ${ }^{2}$ Associate Professor, Department of Community Medicine, IPGMER, Kolkata; \\ ${ }^{3,4}$ Associate Professor, Department of Community Medicine, College of Medicine and Sagore Dutta Hospital, Kolkata; ${ }^{5}$ Deputy \\ Superintendent, Burdwan Medical College Hospital, Burdwan, West Bengal; ${ }^{6}$ Deputy CMOH-1, Burdwan, West Bengal, India.
}

\begin{abstract}
Under the Revised National Tuberculosis Control Programme (RNTCP), Tuberculosis services are provided free of charge in India; all diagnosed TB patients are initiated on treatment within 7 days. Initial default is a potentially serious problem, particularly in cases of smear positive patients because they may continue transmitting the disease. This study was conducted to estimate the proportion of new sputum positive pulmonary TB patients who dropped out before initiating treatment, and their reasons for not registering for treatment. A cross-sectional study was carried out at Darjeeling District from July 2011 to April 2012 among 132 initial defaulters. Initial defaulter rate was $23.5 \%$. A majority of the defaulters were $15-29$ years old $(59.10 \%)$; male $(70.45 \%)$; from rural areas $(80.06 \%)$; literate $(78.79 \%)$; employed (86.36\%); married (71.97\%); non-smokers $(77.27 \%)$; and had a mean per capita monthly income of Rs 741.40. Age, literacy, employment, marital status, smoking habits, alcohol consumption and pre treatment counseling were associated more among males than females and the differences were statistically significant. Among 'busy with other jobs', $76.19 \%$ of patients were from a rural area, $71.43 \%$ were below the mean age, $73.81 \%$ had below mean per capita income. Among 'temporary vocational migration', $87.8 \%$ of patients were from rural areas, $56.1 \%$ were below the mean age, $63.41 \%$ had below mean per capita income. Among 'idle at home', $78.57 \%$ patients were from rural areas, $60.71 \%$ were below mean age, $75 \%$ had below mean per capita income. There is a need to convince the tuberculosis patients for initiating and completing treatment.
\end{abstract}

Keywords: Pulmonary tuberculosis, Initial default, Sputum positive cases, RNTCP, India.

\section{Introduction}

India is the highest tuberculosis burden (1.98 million) country accounting for one fifth of the global incidence (9.4 million). ${ }^{1}$ Under the Revised National Tuberculosis Control Programme (RNTCP), tuberculosis (TB) services are provided free of charge in India via a network of designated microscopy centers (DMCs) and directly observed treatment (DOT) centres. ${ }^{2,3}$ All diagnosed TB patients are initiated on treatment within 7 days by the health facility closest to the patient's residence. As soon as the patient initiates treatment, feedback is provided to the DMC and this is documented in the RNTCP Laboratory Register. ${ }^{2}$ Initial defaulters are counted at the district level and are reported on a quarterly basis to the state and central units. As they are neither initiated on RNTCP treatment nor recorded in the RNTCP TB Registers, they are not included in the RNTCP quarterly cohort reports on case finding and treatment outcomes. ${ }^{3}$

As a progress indicator, the RNTCP monitors the success in initiating treatment for all diagnosed smear-positive pulmonary TB cases. The RNTCP defines an initial defaulter as 'a diagnosed TB patient who has been recorded in the RNTCP Laboratory Register, but who has neither been placed on an RNTCP regimen nor been referred for treatment under the RNTCP outside the district'. ${ }^{4}$

\section{Practice Points}

- Initial default of TB patients is a potentially serious problem, particularly in cases of smear positive patients because they may continue transmitting the disease.

- The initial defaulter rate was quite high at the Darjeeling District of West Bengal, India.

- The main reason of initial default was 'busy with other job'. Other reasons include temporary vocational migration, idle at home, DOT center closed, dissatisfaction of services, drug out of stock/substandard drug etc.

- Factors reasonably associated with initial default were lower age group, male sex, literate, employed, married, non-smoker, alcohol consumer, rural areas, per capita monthly income below mean income level, pre-treatment counseling and DOT providers from government sector.

- There is a need to convince the tuberculosis patients considering the predicting issues for initiating and completing treatment.

Correspondence: Dr. Palash Das, Associate Professor, Department of Community Medicine, College of Medicine and Sagore Dutta Hospital, Kolkata, West Bengal, India. Emil: palashdasdr@gmail.com. 
Initial default indicates low capacity of the program to find the patient and inform about diagnosis. ${ }^{5}$ Initial defaults of smear positive cases can be easily measured as the results and address or origins of the samples are recorded in the laboratory register. Initial default is a potentially serious problem, particularly in cases of smear positive patients because they continue transmitting the disease. ${ }^{5}$ This initial default is a preventable matter. This is again regrettable that this is still highly prevalent in our society where program for control of tuberculosis is working.

A patient with active pulmonary tuberculosis expels infectious droplets of 0.5 to 5 microns during coughing, sneezing or speaking. ${ }^{6}$ Infectious dose of tuberculosis is very low; even a single bacterium can cause a new infection. ${ }^{1}$ Besides one smear positive patient infects 10 -15 persons in a year and $10 \%$ of them will develop the disease in due course. ${ }^{7}$ Thus there is a need to trace and register these initial defaulters for treatment to prevent further transmission.

Several studies examined the problem of default after initiation of treatment. ${ }^{8,9}$ However, the issue of default before initiation of treatment of tuberculosis has been studied to a limited extent only. A study conducted by Balasubramanian $^{10}$ in Tiruvallur district reported an initial default rate of $29 \%$ among patients in a community survey as compared to $15 \%$ among those attending government health facilities. Darjeeling district has $79 \%$ cure rate of new sputum smear positive (NSP) TB. ${ }^{11}$ This is far below the desired level. Treatment initiation may be one of the considerations.

Darjeeling is epidemiologically important district regarding tuberculosis. It has the highest case finding rate $(326 / 100,000)$ in West Bengal and one of the highest death rate suggesting high rates of transmission and late case recognition. ${ }^{12}$ Geographically it has diverse terrain with lots of difficulty to reach the target areas. It was the last district to implement RNTCP in West Bengal (December 2004) but one of the first district to start DOTS Plus due to high failure rate $(11 \%)^{12}$ of Cat II patients and MDR (multi-drug resistant) TB.

DOTS Plus was started in Darjeeling district in October 2009. Treatment in this district may be related to initial default and it should be unfolded. This will help the program managers to take required steps in order to place the defaulters into treatment in right time ultimately to reduce transmission, morbidity and mortality due to tuberculosis. During 2011, percentage of all smear-positive cases started RNTCP-DOTS within 7 days of diagnosis was $87 \%$ in India, $80 \%$ in West Bengal and $79 \%$ in Darjeeling District. ${ }^{13}$

With this background, the present study was conducted to estimate the proportion of new sputum positive pulmonary TB patients who dropped out before initiating treatment in RNTCP (initial default) and distribution of the reasons for not registering for treatment with relation to some socio-demographic variables.

\section{Materials and Methods}

An observational descriptive study, cross- sectional in design, was carried out at Darjeeling district of West Bengal for10 months, from July 2011 to April, 2012. Data were collected from October 2011 up to December 2011. The district of Darjeeling is sub-served by six tuberculosis units (TU). Considering the feasibility, this study was carried out in one third of those units. In this way, two tuberculosis units namely Kharibari and Siliguri were selected randomly for the study.

Our study population was total number of initial defaulters of those two tuberculosis units during the data collection period and one month prior to that. Sampling technique was continuous enumeration of the initial defaulters found within the study duration and one month prior to that in the selected TUs. The number came out to be 132 which was our sample size. Study variables were age, sex, marital status, education, occupation, residence, per capita monthly income, smoking habit, alcohol consumption, whether pre-treatment counseling was done or not, whether DOT provider from government sector or private sector and main reason for initial default.

The study tools were a pre-designed pre tested semi-structured pro-forma( prepared in consultation with three (3) experts of community medicine, pre tested, modified and validated by another 3 experienced persons of community medicine), different registers of RNTCP (such as OPD Register, Laboratory register, Referral for Treatment register, Monthly PHI Report, Tuberculosis Register, Quarterly report of TU TB).

The pro-forma had two parts: patient profile (part 1: socio-demographic factors) and main reasons of nonregistering for treatment (part 2). Study technique was interviewing the initial defaulted cases at their residence. Inclusion criteria were all people diagnosed with new smear-positive TB (at least one positive smear) at those two TB units (TU) in 2011 and who had not been registered for treatment at the TU within 7 days of diagnosis. Exclusion criteria were as per RNTCP definition of 'initial defaulter'. Cases with documented referral for treatment outside the district were excluded.

After obtaining ethical clearance from the Ethical Committee of All India Institute of Hygiene \& Public Health (AIIH \& PH), Kolkata, PHI/multipurpose workers/PHN/STS/STLS were trained and sensitized in data collection in the office of the District Tuberculosis Officer (DTO) by primary investigator (PI) with prior permission from Chief Medical Officer of Health, Darjeeling district. Patients' addresses were retrieved from the laboratory registers and patients were interviewed in their homes. The patients were explained about the purpose of the study and after a written consent was obtained from them, they were recruited for the study. The participation was voluntary and they were assured about confidentiality and anonymity. The enrolled initial defaulters were interviewed by the health workers using the predesigned pre-tested semi 
structured pro-forma. Approximately $60 \%$ patients were visited by STS/STLS.

In case of absence at residence, an attempt was made to contact the cases at least thrice. To maintain the quality of data, $20 \%$ of the initial defaulters were re-interviewed by primary investigator as a method of cross check. An information sharing meeting with the Health Care Providers and participants after completion of the study was conducted to answer the queries raised by the study population.

Finally, the collected data were tabulated, analyzed and interpreted by application of proper statistical methods (proportions, Chi square test) to assess association between various factors and default. P-value of $<0.05$ was considered statistically significant. The analysis was done in Microsoft excel 2010, Epi-info 7 and SPSS 19.

\section{Operational definitions:}

Smear-positive pulmonary TB: A patient with one or two smears positive for AFB out of the two sputum specimens subjected for smear examination by direct microscopy. ${ }^{14}$

New cases: A TB patient who has never had treatment for $\mathrm{TB}$ or has taken anti-TB drugs for less than one month. ${ }^{14}$

Initial default: New diagnosed sputum smear positive TB patient who has been recorded in the RNTCP Laboratory Register, but who has neither been placed on an RNTCP regimen within 7 days of diagnosis nor been referred for treatment under the RNTCP outside the district.

Alcohol consumption: One who drinks alcohol every day during the study period.

Smoker: Smoking at least 100 cigarettes in their lifetime and who, at the time of survey, smoked either every day or some days. ${ }^{15}$

Pre-treatment counseling: for TB diagnosis and treatment initiation - counseling done when the client comes for the test results and before TB treatment is initiated for those who test positive. ${ }^{16}$

Temporary Vocational Migration: Mobility of workers from areas with high unemployment to growing areas within countries and across Member States.

Idle at home: To pass time without working or while avoiding work, lazy.

Busy with other jobs: actively and attentively engaged in work or a pastime: busy with work.

DOT centre: The place of consumption of anti-TB drugs under supervision by a designated provider.

Dissatisfaction of services: Services are not good quality and provided in hurry.
Drug out of stock/substandard drug: Substandard medicines (also called out of specification (OOS) products) are genuine medicines produced by manufacturers which do not meet quality specifications set for them by national standards.

\section{Results}

The response rate was cent percent in this study. The distribution of initial defaulters according to their socio demographic profiles and gender were shown in Table 1. Mean age of the study population was 33.48 years with SD 14.49. Majority belonged to lower age group, i.e., below 35 years $(59.1 \%)$; male $(70.45 \%)$; from rural area $(80.06 \%)$; literate $(78.79 \%)$; employed $(86.36 \%)$; married (71.97\%); and non smoker (77.27\%). A little more than half of the participants $(50.76 \%)$ consumed alcohol. Their mean per capita monthly income was Rs 741.4 / with SD 457.3 More than two third (68.18\%) had their per capita monthly income below mean level. Most of the study populations were given pre-treatment counseling $(65.16 \%)$ and their DOT providers were from government sector $(77.27 \%)$.

Factors reasonably associated with initial default were lower age group (below 35 years), male sex, literate, employed, married, non-smoker, alcohol consumer, from rural areas, per capita monthly income (PCMI) below mean income level, pre-treatment counseling done and DOT providers were appointed from government sector (Table 1).

When their socio demographic variables were compared as per gender, it was seen that the variables like age, literacy, employment, marital status, smoking habit, alcohol consumption and pre treatment counseling were more among males than females and the differences were statistically significant $(p<0.05)$. However, their residence, PCMI and type of DOT provider were not significantly associated by gender (Table 1 ).

The main reason given by the 132 patients for initial default included: i) 'busy with other job' $(31.82 \%)$; ii) 'temporary vocational migration' $(31.06 \%)$; iii) 'idle at home' (21.21\%); iv) 'DOT center closed' (5.30\%); v) 'dissatisfaction of services' $(2.27 \%)$; vi) 'drug out of stock/substandard drug' $(2.27 \%)$ and vii) others (treatment from general practitioners and long distance $(6.06 \%)$; though the gender differences were not statistically significant $(\mathrm{p}>0.05)$ (Table 2$)$.

Among 'busy with other jobs', 76.19\% patients were from rural area, $71.43 \%$ were below mean age $(33.48$ years), $73.8 \%$ had below mean per capita income (Rs741.4). Among 'temporary vocational migration', $87.8 \%$ patients were from rural area, $56.1 \%$ were below mean age, $63.41 \%$ had below mean per capita income. Among 'idle at home', 78.57\% patients were from rural area, $60.71 \%$ were below mean age, $75 \%$ had below mean per capita income. However, these were not statistically significant when compared gender wise $(\mathrm{p}>0.05)($ Table 3$)$ 
Table 1: Socio-demographic characters as per gender of the study population $(n=132)$

\begin{tabular}{|c|c|c|c|c|c|}
\hline Criteria & Sub- Criteria & $\begin{array}{l}\text { Male } \\
\text { n (\%) }\end{array}$ & $\begin{array}{c}\text { Female } \\
\text { n }(\%)\end{array}$ & $\begin{array}{l}\text { Total } \\
\text { n }(\%) \\
\end{array}$ & $\chi^{2}$, P value \\
\hline \multirow[t]{2}{*}{ Age } & $<35$ years & $47(50.54 \%)$ & $31(79.49 \%)$ & $78(59.10 \%)$ & \multirow{2}{*}{$\begin{array}{l}\chi^{2}-9.53 \\
p-0.002\end{array}$} \\
\hline & $\geq 35$ years & $46(49.46 \%)$ & $08(20.51 \%)$ & $54(40.90 \%)$ & \\
\hline \multirow[t]{2}{*}{ Education } & Illiterate & $15(16.13 \%)$ & $13(33.34 \%)$ & $28(21.21 \%)$ & \multirow{2}{*}{$\begin{array}{l}\chi^{2}-4.87 \\
p-0.027\end{array}$} \\
\hline & Literate & $78(83.87 \%)$ & $26(66.66 \%)$ & $104(78.79 \%)$ & \\
\hline \multirow[t]{2}{*}{ Occupation } & Unemployed & $09(09.68 \%)$ & $09(23.08 \%)$ & $18(13.64 \%)$ & \multirow{2}{*}{$\begin{array}{l}\chi^{2}-4.19 \\
p-0.041\end{array}$} \\
\hline & Employed & $84(90.32 \%)$ & $30(76.92 \%)$ & $114(86.36 \%)$ & \\
\hline \multirow{2}{*}{$\begin{array}{l}\text { Pre-Treatment coun- } \\
\text { seling done }\end{array}$} & Yes & $53(56.99 \%)$ & $33(84.62 \%)$ & $86(65.16 \%)$ & \multirow{2}{*}{$\begin{array}{l}\chi^{2}-9.24 \\
p-0.002\end{array}$} \\
\hline & No & $40(43.01 \%)$ & $06(15.38 \%)$ & $46(34.84 \%)$ & \\
\hline \multirow[t]{2}{*}{ Marital status } & Married & $62(66.67 \%)$ & $33(84.62 \%)$ & $95(71.97 \%)$ & \multirow{2}{*}{$\begin{array}{l}\chi^{2}-4.39 \\
p-0.036\end{array}$} \\
\hline & Unmarried & $31(33.33 \%)$ & $06(15.38 \%)$ & $37(28.03 \%)$ & \\
\hline \multirow[t]{2}{*}{ Smoking habit } & Yes & $28(30.11 \%)$ & $02(05.13 \%)$ & $30(22.73 \%)$ & \multirow{2}{*}{$\begin{array}{l}\chi^{2}-9.76 \\
p-0.002\end{array}$} \\
\hline & No & $65(69.89 \%)$ & $37(94.87 \%)$ & $102(77.27 \%)$ & \\
\hline \multirow{2}{*}{$\begin{array}{l}\text { Alcohol consump- } \\
\text { tion }\end{array}$} & Yes & $59(63.44 \%)$ & $08(20.51 \%)$ & $67(50.76 \%)$ & \multirow{2}{*}{$\begin{array}{l}\chi^{2}-20.3 \\
p-0.000\end{array}$} \\
\hline & No & $34(36.56 \%)$ & $31(79.49 \%)$ & $65(49.24 \%)$ & \\
\hline \multirow[t]{2}{*}{ Residence } & Urban & $15(16.13 \%)$ & $10(25.64 \%)$ & $25(18.94 \%)$ & \multirow{2}{*}{$\begin{array}{l}\chi^{2}-1.62 \\
p-0.203\end{array}$} \\
\hline & Rural & $78(83.87 \%)$ & $29(74.36 \%)$ & $107(80.06 \%)$ & \\
\hline \multirow{2}{*}{$\begin{array}{l}\text { Per capita monthly } \\
\text { Income (PCMI) }\end{array}$} & Below mean income & $61(65.59 \%)$ & $29(74.36 \%)$ & $90(68.18 \%)$ & \multirow{2}{*}{$\begin{array}{c}\chi^{2}-0.974 \\
p-0.324\end{array}$} \\
\hline & Above mean income & $32(34.41 \%)$ & $10(25.64 \%)$ & $42(31.82 \%)$ & \\
\hline \multirow[t]{2}{*}{ DOT provider } & Government & $70(75.27 \%)$ & $32(82.05 \%)$ & $102(77.27 \%)$ & \multirow{2}{*}{$\begin{array}{c}\chi^{2}-0.720 \\
p-0.396\end{array}$} \\
\hline & Private & $23(24.73 \%)$ & $07(17.95 \%)$ & $30(22.73 \%)$ & \\
\hline Total & & $93(70.45 \%)$ & $39(29.55 \%)$ & $132(100.00 \%)$ & \\
\hline
\end{tabular}

Degrees of freedom $(\mathrm{df})=1$

Table 2: Main reasons for Initial Default according to the study population $(n=132)$

\begin{tabular}{|l|c|c|c|c|}
\hline Reasons & \multicolumn{1}{|c|}{$\begin{array}{c}\text { Male } \\
\mathbf{n}(\mathbf{\%})\end{array}$} & $\begin{array}{c}\text { Female } \\
\mathbf{n}(\mathbf{\%})\end{array}$ & $\begin{array}{c}\text { Total } \\
\mathbf{n}(\mathbf{\%})\end{array}$ & $\begin{array}{c}\chi^{\mathbf{2}} \mathbf{p} \\
\text { value }\end{array}$ \\
\hline Drug out of stock/substandard drug & $02(02.15 \%)$ & $01(02.56 \%)$ & $03(02.27 \%)$ & \\
\hline Dissatisfaction of services & $02(02.15 \%)$ & $01(02.56 \%)$ & $03(02.27 \%)$ & \\
\hline DOT center closed & $05(05.38 \%)$ & $02(05.13 \%)$ & $07(05.30 \%)$ & $\chi^{2}-$ \\
\hline Busy with other jobs & $29(31.18 \%)$ & $13(33.33 \%)$ & $42(31.82 \%)$ & 0.178, \\
\hline Idle at home & $20(21.50 \%)$ & $08(20.51 \%)$ & $28(21.21 \%)$ & $p-0.99$ \\
\hline Temporary Vocational Migration & $29(31.18 \%)$ & $12(30.78 \%)$ & $41(31.06 \%)$ & \\
\hline Others (treatment from GPs, long distance etc.) & $06(06.45 \%)$ & $02(05.13 \%)$ & $08((06.06 \%)$ & \\
\hline Total & $93(100.00 \%)$ & $39(100.00 \%)$ & $132(100.00 \%)$ & \\
\hline
\end{tabular}

$\mathrm{df}=(7-1)(2-1)=6$

Table 3: Main reasons for initial default according to residence, age and per capita monthly income

\begin{tabular}{|c|c|c|c|}
\hline Reasons & $\begin{array}{c}\text { Urban Number } \\
\text { n (\%) }\end{array}$ & $\begin{array}{c}\text { Rural Number } \\
\text { n (\%) }\end{array}$ & $\chi^{2}, \mathbf{p}$ value \\
\hline Busy with other jobs & $10(23.81 \%)$ & $32(76.19 \%)$ & \multirow{3}{*}{$\begin{array}{c}\chi^{2}-1.98 \\
p-0.37 \\
\mathrm{df}=2\end{array}$} \\
\hline Temporary vocational migration & $05(12.20 \%)$ & $36(87.80 \%)$ & \\
\hline \multirow[t]{2}{*}{ Idle at home } & $06(21.43 \%)$ & $22(78.5 \%)$ & \\
\hline & Below mean age & Above mean age & \\
\hline Busy with other jobs & $30(71.43 \%)$ & $12(28.57 \%)$ & \multirow{3}{*}{$\begin{array}{c}\chi^{2}-2.18 \\
p-0.33 \\
\mathrm{df}=2\end{array}$} \\
\hline Temporary Vocational Migration & $23(56.10 \%)$ & $18(43.90 \%)$ & \\
\hline \multirow[t]{2}{*}{ Idle at home } & $17(60.71 \%)$ & $11(39.29 \%)$ & \\
\hline & Below mean income & Above mean income & \\
\hline Busy with other jobs & $31(73.81 \%)$ & $11(26.19 \%)$ & \multirow{3}{*}{$\begin{array}{c}\chi^{2}-1.47 \\
p-0.47 \\
\mathrm{df}=2\end{array}$} \\
\hline Temporary Vocational Migration & $26(63.41 \%)$ & $15(36.59 \%)$ & \\
\hline Idle at home & $21(75.00 \%)$ & $07(25.00 \%)$ & \\
\hline
\end{tabular}




\section{Discussion}

The question often arises why some patients initiate treatment of tuberculosis successfully while others don't under comparable conditions. Seeking answer in this direction, a cross sectional study was undertaken among initial defaulters. As a smear positive patient infects 1015 persons in a year and $10 \%$ of them will develop the disease in due course, ${ }^{17}$ so the causes must be defined out.

\section{Magnitude of Initial default:}

In the present study, the initial defaulter rate was $23.5 \%$; the result of which was corroborative to some other previous studies in India and abroad. ${ }^{18-23}$ A study by Rao et al. ${ }^{18}$ at Karachi observed high initial default rate (27.7\%); another study by Botha et al. ${ }^{19}$ at Cape Town recorded $16 \%$ as initial defaulter rate ; a South India study by Gopi et $a .^{20}$ revealed $23.5 \%$ and $14.9 \%$ initial defaulter rate in community survey and health facility survey respectively; a South Africa study by Botha et $a l^{21}$ showed initial defaulter rate of $17 \%$; a study carried out at Sandur TU of Bellary District, Karnataka by Ahmed et al ${ }^{22}$ demonstrated $18.5 \%$ initial defaulter rate; and a retrospective cohort study at New Delhi by Kumar et $a l^{23}$ observed initial defaults among locally-residing smear-positive TB patients diagnosed at National Institute of Tuberculosis \& Respiratory Diseases (NITRD) was $21 \%$.

However, some other studies revealed quite lower initial defaulter rate. ${ }^{3,24} \mathrm{~A}$ study conducted by Babu et al. ${ }^{3}$ at Andhra Pradesh revealed that nearly 5\%of smear-positive pulmonary TB patients diagnosed in the study period were confirmed as not having initiated treatment under the Revised National Tuberculosis Control Programme and another study by Buu et $a l^{24}$ at Vietnam reported a low initial default rate of $8.3 \%$. In contrast, Ghana study by Afutu et $a{ }^{25} .^{25}$ demonstrated a high initial defaulter rate $(38 \%)$ which requires improvement in the quality of health services.

\section{Reasons for initial default:}

In our study the main reason given by the study population was busy with other job. Other reasons included: temporary vocational migration, idle at home, DOT center closed, dissatisfaction of services, drug out of stock/substandard drug etc. These findings were consistent with other previous studies. ${ }^{18-20,22,24}$ 'Drug out of stock' is not acceptable phenomenon now a day in present day program. In-depth interview of program managers may answer to this un-wanted phenomenon.

In Karachi study ${ }^{18}$ the most common reasons for non initiating treatment were dissatisfaction of services $(33.33 \%)$ followed by taking treatment from General Practitioners $(25 \%)$, substandard drugs given at clinic $(20.8 \%)$, not aware of the disease $(16.6 \%)$ and did not bother to collect the report and long distance (4.2\%). Another study at Cape Town ${ }^{19}$ recorded the reasons for non starting treatment were $56 \%$ directly related to services and rest $44 \%$ were not linked to services. A South India study $^{20}$ revealed the reasons given by community survey participants were unwillingness for initiation of treatment, symptoms too mild to warrant treatment, too sick/old and work related problems and the reasons for default given by health facility survey participants were personal problems like loss of wages, social engagements, dissatisfaction with health services, feel better or too sick. The study at Sandur TU of Bellary District, Karnataka ${ }^{22}$ showed that the main reason was probably because of the problems associated with loss of wages. Another study conducted in Vietnam $^{24}$ reported that $79.5 \%$ patients defaulted due to issues related to health facility whereas $17.5 \%$ gave reasons related to insufficient knowledge.

\section{Association of initial default in relation to Gender:} In this study, when their socio demographic variables were compared as per gender, it was seen that the initial defaulter rate was higher in males than females and variables like age, literacy, employment, marital status, smoking habit, alcohol consumption and pre treatment counseling were more among males than females and the differences were statistically significant; which was similar to some previous studies. ${ }^{20,22}$ The South India study by Gopi et al. ${ }^{20}$ reported initial defaulter rate was higher among males compared to females and the study by Ahmed et al. ${ }^{22}$ at Bellary District, Karnataka also demonstrated the same result probably because of the problems associated with loss of wages. This underlines the need for greater efforts on the part of health workers to motivate male patients for initiating treatment and also to ensure treatment regularity as advised under the program. On the contrary, study at Delhi by Kumar et $a l^{23}$ revealed that female sputum positive TB patients tended towards higher initial default than males; which was dissimilar to the present study.

As dissatisfaction with public health services, treatment from general practitioners and difficulties in repeatedly travelling to diagnostic centers are common in several developing countries, it is felt that the findings were relevant beyond India. These deficiencies can be avoided by improved health services through obtaining correct addresses and additional contact information, encouraging TB suspects to keep PHC facilities informed of their movements, clearly communicating smear and culture results and actively following up initial defaulters. ${ }^{15}$

\section{Limitations}

- Only the patients attending for diagnosis and treatment at public health system are included in the study. As many TB patients go to the private practitioners, these data were missing in this research; so the problem of initial default was underestimated.

- As the interview of the patients was taken by the health workers, the actual facts to some extent may be masked to show good performance. To avoid this, $20 \%$ of the patients were cross-checked by the same schedule by the primary investigator. However some amount of interviewer's bias was inevitable in this study. 
Though the proforma was piloted and the interviewers were trained before data collection, the questions about reason for not registering were a multifactor issue that is difficult to explore in depth. Decision was made to ask the main reason for initial default, which on the one hand over-simplifies the question, but on the other hand is likely to improve reliability. So other issues for non-registering were not counted in this research.

- This study done in a hilly district of West Bengal. Moreover out of six TUs, only two TUs were taken for the study of consideration of the feasibility. The results obtained cannot be extrapolated in general/ wider sense.

- One of the important variables HIV should be included. So TB-HIV co-ordination part was missing in this research.

\section{Strengths}

- This is a relatively new topic as issue of default before initiation of treatment of tuberculosis has been studied to a limited extent only and Darjeeling district has $79 \%$ cure rate of new sputum smear positive (NSP) TB. This is far below the desired level. Treatment initiation may be one of the considerations.

- Darjeeling is epidemiologically important district regarding tuberculosis. It has the highest case finding rate in West Bengal. Geographically it has diverse terrain with lots of difficulty to reach the target areas. It was the last district to implement RNTCP in West Bengal but one of the first district to start DOTS Plus due to high failure rate of Cat II patients and MDR TB.

\section{Conclusion}

Out of the factors studied, significant relationships were found between religion and the occupation of mothers and low birth weight of newborns. Other factors such as age and socio-economic status of the mother were not significantly associated with LBW. Thus, it is a multi-factorial phenomenon. Hence, interventional programs should be encouraged not only in health sectors but in all those sectors concerned with social development and social welfare programs.

\section{Recommendations}

The study put forward the following recommendations:

- Awareness (IEC) regarding early initiation of treatment is required to minimize the knowledge and practice gap.

- As most of the DOT providers are from Government sector more training \& motivation from the health staffs are required.

- There is a need to motivate and improve patient's perception of TB disease and the need for DOTS and convince them of the need for initiating and completing treatment.
- This issue should be analyzed more widely and more studies are needed.

- Supervision and motivation of treatment for male TB cases requires to be strengthened.

\section{References}

1. World Health Organization (WHO). Global TB Report. Geneva: WHO, 2010.

2. Central TB Division (CTD), Directorate General of Health Services, Ministry of Health and Family Welfare, Government of India. Technical and operational guidelines for tuberculosis control. New Delhi: CTD, 2005.

3. Sai Babu B, Satyanarayana AV, Venkateshwaralu G, Ramakrishna U, Vikram P, Sahu $\mathrm{S}$ et al. Initial default among diagnosed sputum smear-positive pulmonary tuberculosis patients in Andhra Pradesh, India. Int J Tuberc Lung Dis 2008;12:1055-8.

4. Central TB Division (CTD), Directorate General of Health Services, Ministry of Health and Family Welfare, Government of India. Strategy document for the supervision and monitoring of the Revised National Tuberculosis Control Programme. New Delhi, India. 2005.

5. RNTCP Operational Research Agenda, 20092010. Interventions to improve treatment outcomes. Int J Tuberc Lung Dis 2004;8:323-2.

6. Cole E, Cook C. Characterization of infectious aerosols in health care facilities: an aid to effective engineering controls and preventive strategies. Am J Infect Control 1998; 26: 453-64.

7. World Health Organization (WHO). Tuberculosis Fact Sheet No 104 - Global and regional incidence. http://www.who.int/ mediacentre/factsheets/fs104/en/ (accessed June 2014)

8. Vijay S, Balasangameswara VH, Jagannatha PS, Saroja VN, Kumar P. Defaults among tuberculosis patients treated under DOTS in Bangalore city: A search for solution. Indian $J$ Tuberc 2003; 50: 185-195.

9. Gupta S, Gupta S, Behera D. Reasons for Interruption of Anti-Tubercular Treatment as Reported by Patients with Tuberculosis Admitted in a Tertiary Care Institute. Indian $J$ Tuberc 2011; 58: 11-7.

10. Balasubramanian R, Garg R, Santha T, Gopi PG, Subramani R, Chandrasekaran V, et al. Gender disparities in tuberculosis: report from a rural DOTS programme in South India. Int $J$ Tuberc Lung Dis 2004;8:323-32.

11. Government of West Bengal. Department of Health \& Family Welfare. Health on the March 2009;10:95-7. 
12. Central TB Division (CTD), Directorate General of Health Services, Ministry of Health and Family Welfare, Government of India. TB India. Annual Status Report. New Delhi: RNTCP, 2011.

13. Central TB Division (CTD), Directorate General of Health Services, Ministry of Health and Family Welfare, Government of India. TB India. Annual Status Report. New Delhi: RNTCP, 2012.

14. Central TB Division (CTD), Directorate General of Health Services, Ministry of Health and Family Welfare, Government of India RNTCP modules for Medical officers. Treatment Services. Modules 3. New Delhi, India.

15. Centers for Disease Control and Prevention. State-specific secondhand smoke exposure and current cigarette smoking among adults United States, 2008. MMWR Morb Mortal Wkly Rep 2009;58:1232-5.

16. PATH. Interpersonal Communication and Counseling for Clients on Tuberculosis and HIV and AIDS. Training curriculum for TB health workers, 2009.

17. Nicas M, Nazaroff WW, Hubbard A. Toward understanding the risk of secondary airborne infection: emission of respirable pathogens. $J$ Occup Environ Hyg 2005;2:143-54.

18. Rao NA, Saleem M, Anwer T. Magnitude of initial default in pulmonary tuberculosis. $J$ Pak Med Assoc 2009;51:223-5.

19. Botha E, Den Boon S, Verver S, Dunbar R, Lawrence KA, Bosman $\mathrm{M}$, et al. Initial default from tuberculosis treatment: how often does it happen and what are the reasons? Int $J$ Tuberc Lung Dis 2008;12:820-3.

20. Gopi P G, Chandrasekaran V, Subramani R, Narayanan P R. Failure to initiate treatment for tuberculosis patients diagnosed in a community survey and at health facilities under a DOTS programme in a district of South India. Indian $J$ Tuberc 2005;52:153-6.

21. Botha E, den Boon SD, Lawrence K A, Reuter $\mathrm{H}$, Verver S, Lombard CJ, et al. From suspect to patient: tuberculosis diagnosis and treatment initiation in health facilities in South Africa. Int J Tuberc Lung Dis 2008;12:936-41.

22. Ahmed J, Chadha VK, Singh S, Venkatachalappa SB, Kumar P. Utilization of RNTCP services in rural areas of Bellary district, Karnataka by gender, age and distance from health centre. Indian J Tuberc 2009; 56:62-8.

23. Kumar S. A Retrospective Cohort Study of the Magnitude of Initial Default Among Sputum Smear-Positive TB Patients Diagnosed at NITRD New Delhi, 4th Quarter 2012. India EIS Conference 2013.

24. Buu TN, Lonnroth K, Quy HT. Initial defaulting in the National Tuberculosis Programme in Ho Chi Minh City, Vietnam: a survey of extent, reasons and alternative actions taken following default. Int J Tuberc Lung Dis 2003;7:735-41.

25. Afutu FK, Zachariah R, Hinderaker SG, Ntoah-Boadi H, Obeng EA, Bonsu FA, et al. High initial default in patients with smear-positive pulmonary tuberculosis at a regional hospital in Accra, Ghana.Trans $R$ Soc Trop Med Hyg. 2012;106:511-3. 